\title{
Effect of water on the breakdown and dielectric response of polypropylene/nano-aluminium nitride composites
}

\author{
Xinyu Wang ${ }^{1, *}$ (D), Dayuan Qiang ${ }^{2}$ (D), Ian Hosier $^{1}$ (D), Yanqiu Zhu ${ }^{2}$ (D), George Chen ${ }^{1}$ (D), and \\ Thomas Andritsch ${ }^{1}$ (1) \\ ${ }^{1}$ Tony Davies High Voltage Laboratory, University of Southampton, Southampton SO17 1BJ, UK \\ ${ }^{2}$ College of Engineering, Mathematics and Physical Sciences, University of Exeter, Exeter EX4 4QF, UK
}

Received: 15 January 2020

Accepted: 31 March 2020

Published online:

16 April 2020

(C) The Author(s) 2020

\begin{abstract}
The influence of water immersion and silane treatment on the AC breakdown and the complex dielectric response of polypropylene/nano-aluminium nitride (PP/nano-AlN) composites has been investigated. The as-received filler was examined to have a nanoscale particle distribution with a hexagonal shape and slight hydrolysation. Grafting the aluminium nitride with an octyl silane reduces the weight increase in samples filled with $10 \mathrm{wt} \%$ of aluminium nitride during water immersion by 3 , from 0.29 to $0.09 \%$. The results suggest that the AC breakdown strength and complex permittivity of "wet" composite samples are related to the silane treatment of the nanofiller. The AC breakdown strength of octyl silane-treated samples after 9 days of water immersion shows comparable results to the dry samples, while a reduction can be seen on non-treated samples. Although silane-treated samples still show an increased dielectric loss at low frequency after water immersion, a significant reduction in low-frequency dispersion of real and imaginary permittivity can be seen when compared to the non-treated composites. This indicates that significant gains can be obtained for PP/nano-AlN composites by suitable silane treatments.
\end{abstract}

\section{Introduction}

Polypropylene (PP) is considered a potential nextgeneration high-voltage cable insulation material by many researchers due to its potential to permit higher cable operating temperatures compared to traditional cross-linked polyethylene (XLPE) [1, 2]. Owing to its thermoplastic nature and the elimination of a cross- linking step, its environmental impact is significantly reduced compared to XLPE over the full life cycle of a cable [3]. However, PP cable insulation suffers from a number of drawbacks regarding thermo-mechanical properties; one of them is having a low thermal conductivity, which is $0.14 \mathrm{~W} \mathrm{~m}^{-1} \mathrm{~K}^{-1}$ [4]. This drawback can be overcome by adding fillers with high thermal conductivity, which also can help

Address correspondence to E-mail: xw2n14@soton.ac.uk 
alleviate the issue of high thermal gradients between the inner and outer of the cable insulation [5-7]. This issue can lead to localised regions of higher conductivity/higher dielectric loss which can shorten the lifetime of the cable. In addition to this, improved dielectric properties achieved by incorporating nanoparticles into polymer insulation have been reported widely [8-10]. The large interfacial area associated with nanoparticles means that a relatively small filler loading $(\leq 5 \mathrm{wt} \%)$ can significantly influence bulk dielectric properties. However, water absorption can be an issue due to the ubiquitous nature of water in the environment and the fact that most of the commonly used inorganic nanofillers, e.g. oxides like $\mathrm{SiO}_{2}, \mathrm{Al}_{2} \mathrm{O}_{3}$ and $\mathrm{MgO}$, tend to make the composite material hydrophilic and hence susceptible to water absorption during both material production and operation, which can severely deteriorate the dielectric properties [11, 12]. A water shell model was proposed by Zou et al. [13, 14] in which conduction pathways tend to form around nanoparticles and behave as "water shell". This, given the presence of sufficient water, can result in a significant decrease in the DC breakdown strength and a corresponding increase in the electrical conductivity. Although a higher DC conductivity can sometimes lead to an increased AC breakdown strength [15], in DC cable applications, the increased electrical conductivity will tend to shorten the cable lifetime.

It is reported that nano-boron nitride $(\mathrm{BN})$ and nano-aluminium nitride/polyethylene composites show significantly higher hydrophobicity than polyethylene filled with oxide fillers [11, 16]. It is worth mentioning that the size distribution of aluminium nitride (AlN) used in previous work [11] was observed to vary from nano- to micro-size and the lower water uptake can be the result of the smaller particle surface area, rather than the surface properties; the same issues of having AlN with a wide size distribution were also found elsewhere [17, 18]. Therefore, in the present work, AIN from a different supplier was used, and the size distribution was verified.

Silane functionalisation was applied in order to increase the hydrophobicity of $\mathrm{PP} /$ nano-AlN composites further. It is widely reported that grafting non-polar silane onto the nanoparticle surface can reduce water absorption, and the influence of its chain length was investigated [12, 19, 20]. Silane coupling agents (SCA) are commonly used in composite materials to increase the compatibility between inorganic fillers and polymers, and an improved particle dispersion can be obtained by silane functionalising the filler surface [21]. The selection of SCA is usually based on the compatibility between its organofunctional group and the polymer matrix, e.g. the epoxide silanes are widely used in epoxy nanocomposites, since the formation of the covalent bond can bring many useful properties, like a reduced permittivity and an increased AC breakdown strength [22-24]. However, there is still a lack of convincing evidence that shows that SCA can form covalent bonds with PP in the same way as observed in epoxy. Alkyl silanes are considered to be a good choice, since the repeating $\left(\mathrm{CH}_{2}\right)_{\mathrm{n}}$ structure of its organofunctional group can provide compatibility with PP. Their non-polar nature is also expected to confer favourable degrees of hydrophobicity. Zhao et al. [25] demonstrated that methacrylate silane could enhance interfacial interaction between inorganic filler and PP host. The mechanical properties, such as the tensile strength, are typically noticeably enhanced, but in our case, the introduction of polar groups-like methacrylate-might result in little or no change in terms of the hydrophobicity of the composites. Apart from the organofunctional groups, the microstructure of the grafting layer can also lead to a change in bulk properties. Yeung et al. [24] reported that the $\mathrm{AC}$ breakdown strength and the complex permittivity of nanosilica-epoxy composites were related to the thickness of the silane layer; hence, the amount of SCA introduced is important. For polyolefin/nanoparticle composites, the absorbed water is typically located on the surface of the filler, rather than the hydrophobic polymer matrix [14]. Investigating samples treated under different humidity conditions is an effective method that can identify the properties of the surface of the nanoparticles. Our previous work also suggests that the potentially different grafting mechanisms related to the different hydrolysable groups of silanes can potentially result in minor differences in the dielectric losses at low frequencies [5]. One possible explanation is the silane functionalised nanoparticles can have a different amount of non-grafted -OH groups from silane, which will result in a different hydrophobicity of corresponding composites (illustrated in Fig. 1a, outstretched Si-OH). Therefore, two alkyl silanes and a methacrylate silane are selected to 
(a)

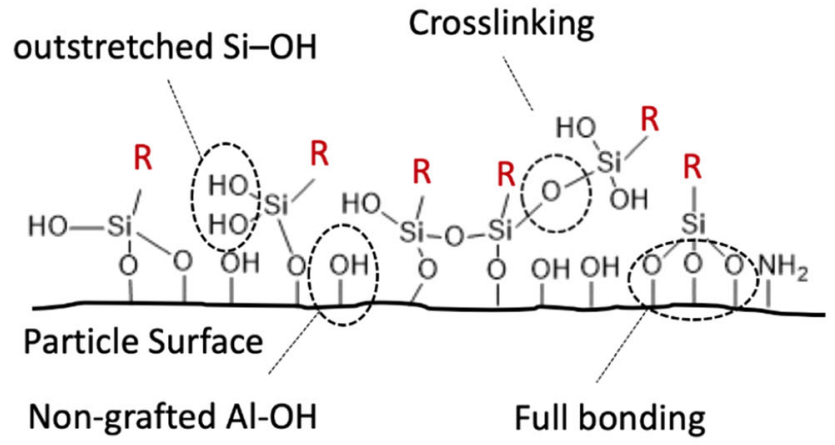

(b)

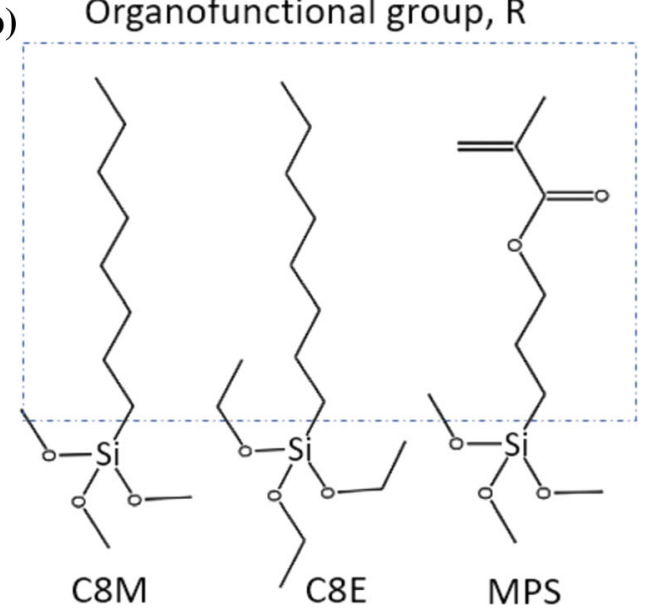

Figure 1 Illustration diagrams of a proposed nano-AlN surface microstructure after silane treatment and $\mathbf{b}$ three different silanes used in present work.

examine the effect of water on the dielectric properties of $\mathrm{PP} /$ nano-AlN composites, namely trimethoxy (octyl) silane (C8M), triethoxy (octyl) silane (C8E) and 3-(trimethoxysilyl) propyl methacrylate (MPS) (Fig. 1b).

\section{Experimental}

\section{Materials and sample preparation}

Nanoscale aluminium nitride (AIN) with an average size of $50 \mathrm{~nm}$ and C8M was obtained from Aladdin Inc. C8E, MPS and PP with a melt index of $4 \mathrm{~g} /$ $10 \mathrm{~min}$ at $230{ }^{\circ} \mathrm{C} / 2.16 \mathrm{~kg}$ were purchased from Sigma-Aldrich.

AlN was surface treated with three different SCA, following a process established in previous work [26]. Probe sonication (Hielscher ${ }^{\circledR}$ UP200S) was applied for $1 \mathrm{~h}$ to disperse $2 \mathrm{~g}$ of AlN in $20 \mathrm{ml}$ toluene, and the required amount of SCA was dissolved in $20 \mathrm{ml}$ of toluene and then added to this solution. This mixture was heated and stirred at $140{ }^{\circ} \mathrm{C}$ for $4 \mathrm{~h}$, and the resulting slurry was then washed three times with toluene. The treated AlN was vacuum-dried at $80^{\circ} \mathrm{C}$ for $24 \mathrm{~h}$. Fourier-transform infrared spectroscopy (FTIR) and thermal gravimetric analysis (TGA) verification of the treated AlN can be found in previous work, where it is evident that the silane functionalisation was successful $[5,26]$.

A modified form of solution blending was applied in this work, which is expected to give a more consistent dispersion state than the method used previously [5], where a hand mixing step was included. Initially, 4.5-4.95 $\mathrm{g}$ of PP was added to $50 \mathrm{ml}$ of xylene and heated at $140{ }^{\circ} \mathrm{C}$ for $30 \mathrm{~min}$, while stirring at $200 \mathrm{rpm}$. The required amount of treated and nontreated AlN (0.05-0.5 g) was dispersed in $10 \mathrm{ml}$ of xylene and sonicated for $30 \mathrm{~min}$. This was then poured into the $\mathrm{PP} /$ xylene mixture and magnetically stirred for another $60 \mathrm{~s}$ at $300 \mathrm{rpm}$ to avoid re-agglomeration. The PP/xylene/AlN was then removed from the heat and poured into $90 \mathrm{ml}$ of methanol inducing precipitation. The resulting mixture was dried at room temperature for 1 day after filtration. It was then put in a vacuum oven at $80{ }^{\circ} \mathrm{C}$ for 3 days to remove any trace of the solvent. The obtained composites were pressed at $180{ }^{\circ} \mathrm{C}$ into sheets and then further processed and pressed into film samples (quenched in water) suitable for different tests.

To analyse the effect of water on the dielectric properties of different samples, two sample conditions were examined: dry (designated D) and wet (W) samples, after immersion in de-ionised water for 9 days. Samples are denoted as $X-Y-Z$, where $X$ represents the surface states (either $N, C 8 M, C 8 E$ or MPS, where $\mathrm{N}$ refers to the non-treated AlN for reference), and $\mathrm{Y}$ is the loading ratio by $w \mathrm{t} \%$ (either 1 , 2.5, 5 or 10). $\mathrm{Z}$ is the conditioning of the sample (either $\mathrm{D}$ or $\mathrm{W}$ ), e.g. C8M-2.5-D is PP filled with $2.5 \mathrm{wt} \%$ of C8M-treated AlN under dry condition. Non-filled PP samples are denoted as PP-D and PP-W for dry and wet condition, respectively. Reference samples, which have been treated with the same solution 
blend procedure as described above, are denoted as PP.

\section{Characterisation techniques}

Scanning electron microscope (SEM) images of AIN were obtained by using a Zeiss $\mathrm{EVO}^{\circledR} 50$, and powders were brushed on a conductive tape and then gold-coated before being examined. For PP and composite samples, an additional permanganic etching procedure in [27] was applied for $10 \mathrm{~h}$ before the samples were gold-coated and then analysed by SEM. Transmission electron microscopy (TEM) of AlN was performed using a JOEL-2100 TEM operated at $200 \mathrm{kV}$. The powders were dispersed in isopropyl alcohol (IPA) in a water sonication bath for $20 \mathrm{~min}$, before being transferred onto a standard carbon film-coated $\mathrm{Cu}$ TEM grid. X-ray diffraction (XRD) patterns of as-received AlN, PP and their composites were taken by a Bruker D8 Advance diffractometer using a $\mathrm{Cu} \mathrm{K} \alpha$ radiation $(\lambda=1.5406 \AA$, $40 \mathrm{kV}$ and $40 \mathrm{~mA}$ ), at a step size of $0.04^{\circ}$ over a $2 \theta$ range from 10 to $80^{\circ}$. Thermal gravimetric analysis (TGA) of as-received AlN was conducted under a nitrogen gas flow $(20 \mathrm{ml} / \mathrm{min})$ from 50 to $900{ }^{\circ} \mathrm{C}$. A temperature increase rate of $10{ }^{\circ} \mathrm{C} / \mathrm{min}$ was applied to compare to the TGA results in [28].

Water absorption analysis was conducted by immersing film samples into de-ionised water, and the weight of the samples was monitored at regular intervals up to 9 days. During the water immersion, film samples were placed in a Petri dish with an immersion depth of $1 \mathrm{~cm}$ in de-ionised water at $20{ }^{\circ} \mathrm{C}$. A glass slide was placed on the top of the sample to avoid the sample floating. Complex permittivities of each system were obtained by testing samples ( $240 \pm 10 \mu \mathrm{m}$ in thickness) with two parallel $30 \mathrm{~mm}$ diameter electrodes. A guard ring electrode was applied according to the ASTM D2149-13 standard. A Solartron 1260A impedance/gain-phase analyser linked to a 1296A dielectric interface system was used, and samples were tested from $10^{-1}$ to $10^{5} \mathrm{~Hz}$ at $20^{\circ} \mathrm{C}$. The AC breakdown strength of each system was obtained by applying a ramped voltage $(1 \mathrm{kV} / \mathrm{s}, 50 \mathrm{~Hz})$ to samples of $115 \pm 15 \mu \mathrm{m}$ thickness. Samples were placed between two ball electrodes (6.3 $\mathrm{mm}$ in diameter) immersed in silicone oil according to the ASTM D149 standard, and the temperature is $20 \pm 2{ }^{\circ} \mathrm{C}$.

\section{Results and discussion-nanoparticles and composites characterisation}

\section{AlN characterisation}

The SEM image of the as-received AlN is shown in Fig. 2. Agglomerations and/or particles from $0.1-20 \mu \mathrm{m}$ can be observed. As the SEM images only show the surface of the "clumps", the morphology and the size of single particles cannot be unambiguously identified.

The TEM image of the as-received AlN is shown in Fig. 3. The shapes of the nanoparticles vary from rods to plates, while the size is within $20-60 \mathrm{~nm}$. An identical result was reported, where nano-AlN from the same manufacturer was used [29]. It is worthy to mention that many inconsistent particle size distribution between observations and the data provided by suppliers has been reported for nano-AlN, including in our previous work [11, 30,31], and we suggested that this could be related to the hydrolytic instability of AlN powders. Li et al. [28] reported that the morphology and particle size distribution of the AlN microparticles are significantly changed after exposure to moist air ( $80 \mathrm{RH} \%$ ) for $400 \mathrm{~h}$ and can have a dehydration weight loss up to $20 \%$ after being heated to $500{ }^{\circ} \mathrm{C}$. A following dehydration process (calcination) of the surface-hydrolysed AlN is reported to form an alumina shell and hinder further hydrolysis [32], and a similar calcination process can be found in many AlN synthesis methods as the last step, e.g. the carbon residue will need to be burnt off at $700{ }^{\circ} \mathrm{C}$ in a carbothermal synthesis method [33]. Therefore, as illustrated in Eqs. 1, 2 and 3, the as-received AlN may contain many products such as $\mathrm{AlOOH}, \mathrm{Al}(\mathrm{OH})_{3}$ and $\mathrm{Al}_{2} \mathrm{O}_{3}$.

$$
\begin{aligned}
& \mathrm{AlN}+\mathrm{H}_{2} \mathrm{O} \rightarrow \mathrm{AlOOH}_{\text {amorph }}+\mathrm{NH}_{3} \\
& \mathrm{AlOOH}_{\text {amorph }}+\mathrm{H}_{2} \mathrm{O} \rightarrow \mathrm{Al}(\mathrm{OH})_{3} \\
& \mathrm{Al}(\mathrm{OH})_{3} \stackrel{\text { calcination }}{\longrightarrow} \mathrm{Al}_{2} \mathrm{O}_{3}+\mathrm{H}_{2} \mathrm{O}
\end{aligned}
$$

The XRD patterns of as-received AlN are shown in Fig. 4. The typical different diffraction peaks assigned to (100), (002), (101), (102), (110), (103) and (112) crystal planes of hexagonal AlN could be found at $2 \theta$ value of $33.2^{\circ}, 35.8^{\circ}, 37.7^{\circ}, 51.7^{\circ}, 59.3^{\circ}, 66.1^{\circ}$ and $71.0^{\circ}$, respectively. However, there is a peak observed at $2 \theta=46.2^{\circ}$, and another merged one at ca. $2 \theta=67.2$, which represent the (400) and (440) peaks of $\gamma-\mathrm{Al}_{2} \mathrm{O}_{3}$. As $\gamma-\mathrm{Al}_{2} \mathrm{O}_{3}$ 
Figure 2 SEM micrographs of a as-received AIN and b selected area of (a) showing aggregations up to 20 to $30 \mu \mathrm{m}$. (a)

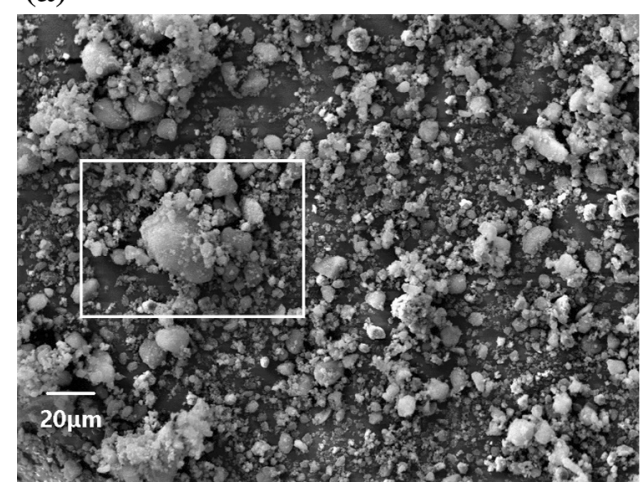

(b)

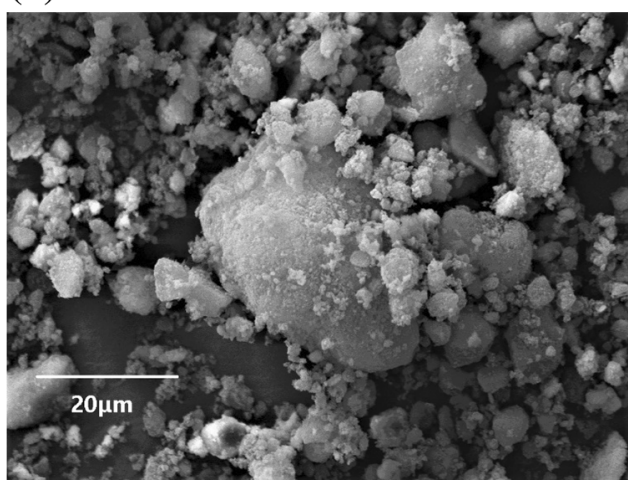

Figure 3 TEM micrographs of a as-received AIN and b selected area of (a) showing the morphology of individual nanoparticles.
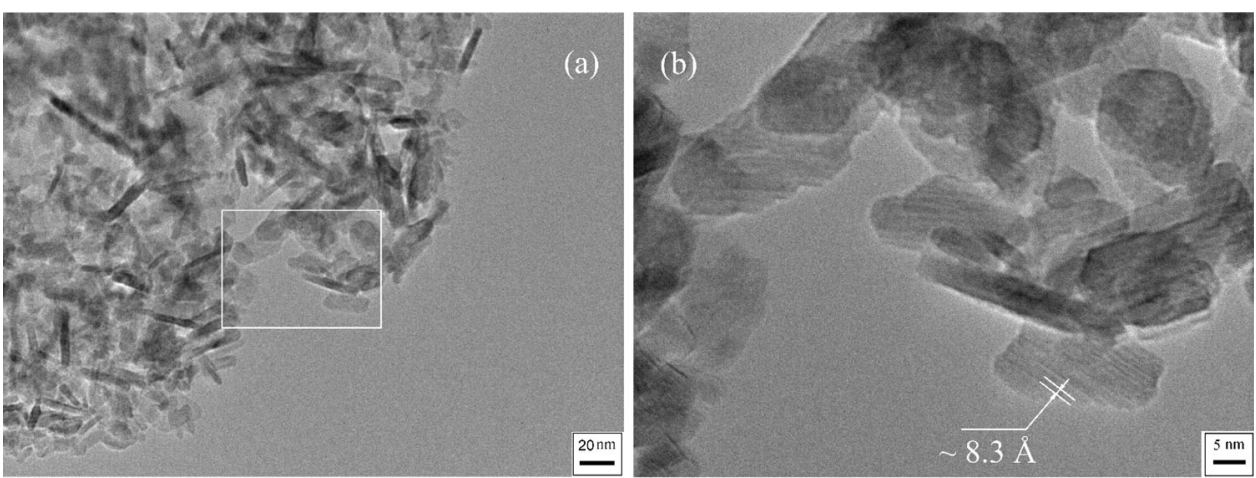

Figure 4 XRD pattern obtained from as-received AlN and features related to hexagonal AlN, and gamma alumina can be observed.

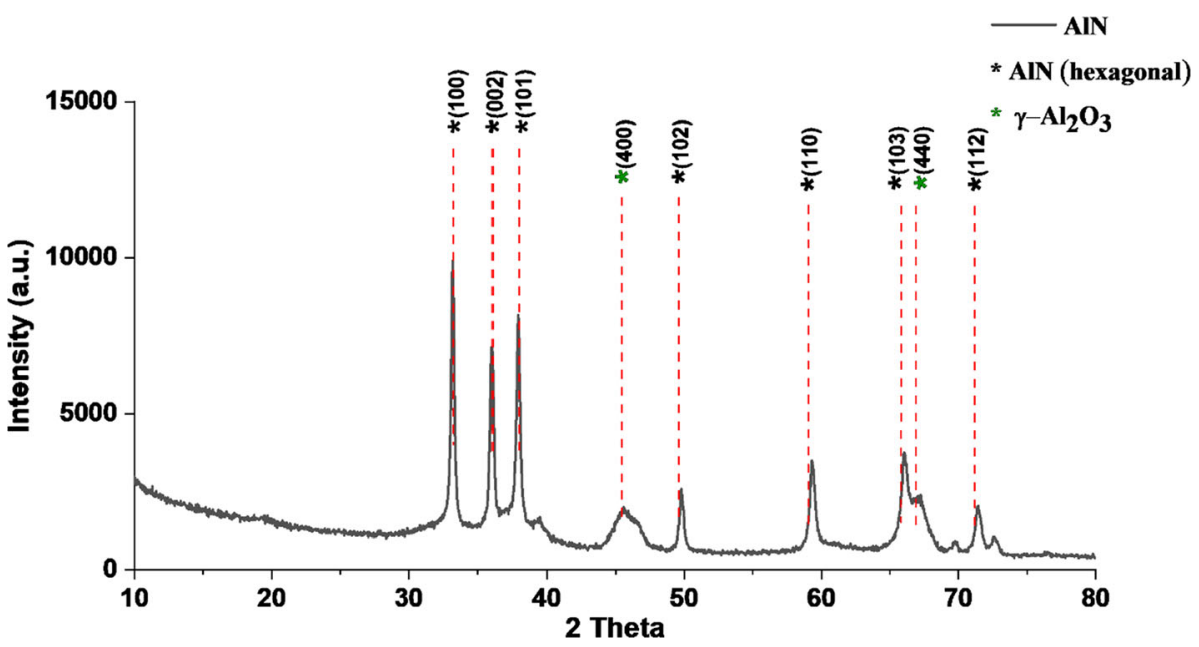

was reported as having a cubic spinel structure [34], in accordance with the $F d \overline{3} m$ space group, with a theoretical lattice parameter of $7.90 \AA$, which was modified by Paglia et al. [35] to 8-20 $\AA$ for real conditions, it is consistent with the observation in the obtained TEM image (Fig. 3b). Here are $\mathrm{Al}_{2} \mathrm{O}_{3}$ nanostructures in the form of plate-like grains which are composed of lamellar crystallites of $5-30 \mathrm{~nm}$ in length and ca. $8.3 \AA$ in thickness. The existence of this kind of $\gamma-\mathrm{Al}_{2} \mathrm{O}_{3}$, which can be a calcinated product of hydrogenated boehmite as expressed in Eq. 4 [35], suggests that the as-received AlN was partially hydrolysed before a calcination process during the manufacturing process, but we cannot rule out the presence of $\gamma-\mathrm{Al}_{2} \mathrm{O}_{3}$ from the $\mathrm{AlN}$ synthesis process [33]. No obvious features of $\mathrm{Al}(\mathrm{OH})_{3}$ crystal structure can be found in XRD patterns, which indicate the hydrolysation of the as-received AlN is in a favourable condition in terms of the hydrolysis issue. 
boehmite or amorph $\mathrm{Al}_{2} \mathrm{O}_{3} \stackrel{\text { calcination }}{\longrightarrow} \gamma-\mathrm{Al}_{2} \mathrm{O}_{3}$

The TGA results of the as-received AlN shown in Fig. 5 also suggest that there is only a slight hydrolysation of the as-received AlN. A wide peak on the derivative TGA curves from 140 to $300{ }^{\circ} \mathrm{C}$ is evident, and both the onset and the peak $\left(190^{\circ} \mathrm{C}\right)$ are lower than these features of a typical dehydration process of $\mathrm{Al}(\mathrm{OH})_{3}$, where a peak on the derivative curve from 200 to $300{ }^{\circ} \mathrm{C}$ centred at $261{ }^{\circ} \mathrm{C}$ can be seen [28]. Thus, this peak is assigned to the combination of loss of the absorbed water and a weak dehydration process of hydrolysed AlN. Water can be found at multiple stages during material production, transport and storage, making hydrolysis of AlN inevitable. Therefore, it is suggested that rigorous material characterisation is essential when working with AlN nanoparticles.

\section{Morphology analysis of PP and PP/nano- AlN composites}

The SEM images of representative samples are shown in Fig. 6. Large aggregations $>30 \mu \mathrm{m}$ can be found in all samples, and some aggregations larger than $80 \mu \mathrm{m}$ can be found in PP with non-treated AlN in Fig. 6c. This is because the polar groups on the AlN surface have poor compatibility with PP and the non-polar solvent applied during the solution blending procedure. The size of large aggregations is reduced with the help of surface modification (Fig. 6c-f), where the

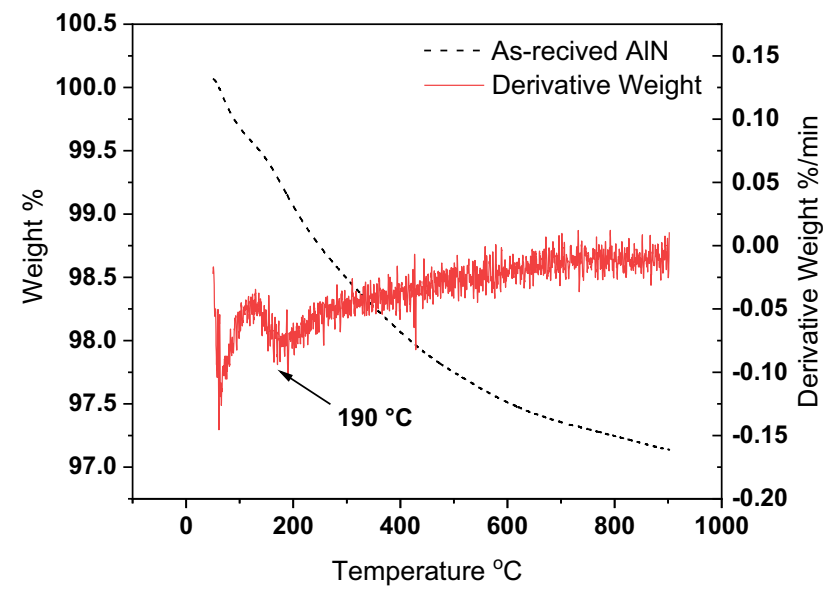

Figure 5 TGA and derivative results of as-received $\mathrm{AlN}$ are obtained by heating AlN from 50 to $900{ }^{\circ} \mathrm{C}$, and a peak on the derivative curve at $190{ }^{\circ} \mathrm{C}$ is related to the dehydration process of hydrolysed AlN on the surface. grafted organic groups can increase the compatibility between AIN and PP. In SEM images of the as-received AlN in Fig. 2, aggregation with size $>20 \mu \mathrm{m}$ is evident, and this is related to the hydrolytic instability of AlN. Aggregations with size $>20 \mu \mathrm{m}$ can also be found in PP with $1 \mathrm{wt} \%$ of surface-treated AlN (Fig. 6b), which indicates that the silane functionalisation in this work could not be able to break the aggregations of AlN. No spherical crystal structure can be observed from SEM in PP samples (Fig. 6a), and this is related to the quenching process, which restricts the growth of the crystalline. Also, the presence of filler will obscure the surface structure of composite materials. Therefore, XRD analysis of the selected samples was conducted, since it is a powerful tool to identify the morphology of the polymer materials.

The XRD patterns of as-received AlN, neat PP and their composites are shown in Fig. 7. The diffraction pattern of the neat PP shows typical peaks at $14.2^{\circ}$, $16.6^{\circ}, 18.5^{\circ}, 21.0^{\circ}, 21.8^{\circ}, 25.5^{\circ}$ and $28.5^{\circ}$ correspond to the (110), (040), (130), (111), (131) + (041), (060) and (220) crystal planes of the $\alpha$-crystals (monoclinic), and the same peaks are also shown in $\mathrm{PP} /$ nano-AlN composites; besides, MPS-10 samples present the $\beta$ crystal (trigonal) peaks at $2 \theta$ of $16.0^{\circ}$ and $21.0^{\circ}$ corresponding to the planes of (300) and (301), respectively. The different results of MPS from others may be due to its methacrylate groups on nanoparticle surface. It is reported polar groups like methacrylate could facilitate more nucleating effect than non-polar ones, e.g. octyl (C8) [5]. This may also be the reason why $(111)+(301)$ and $(131+041)$ planes of MPS-10 are independent from each other, whereas those of C8E-10 and C8M-10 are merged because smaller nucleating ability could limit the dimension of crystallites during the quenching process and broadens the corresponding peaks. Moreover, as N-10 contains non-treated AlN, which has poor dispersion, it could provide more space for the growth of crystallites [5], resulting in narrower peaks and similarly as observed in C8M/C8E with less filler loadings. The broadened peaks in the quenched neat PP could be attributed to the lack of the nucleating effect and resultant smaller size of crystals during quenching. Besides, the intensity of peaks assigned to AIN increases, while the filler loading concentration rises in the composites. A peak between $40^{\circ}$ and $45^{\circ}$ is evident in all samples, including the as-received PP. This is consistent with works with iPP [36, 37], but 
Figure 6 SEM micrographs showing the morphology and AlN dispersion of representative samples: a PP, b C8M-1, c N-10, d MPS-10, e C8M-10, $\mathbf{f}$ and $\mathbf{g}$ C8E-10.
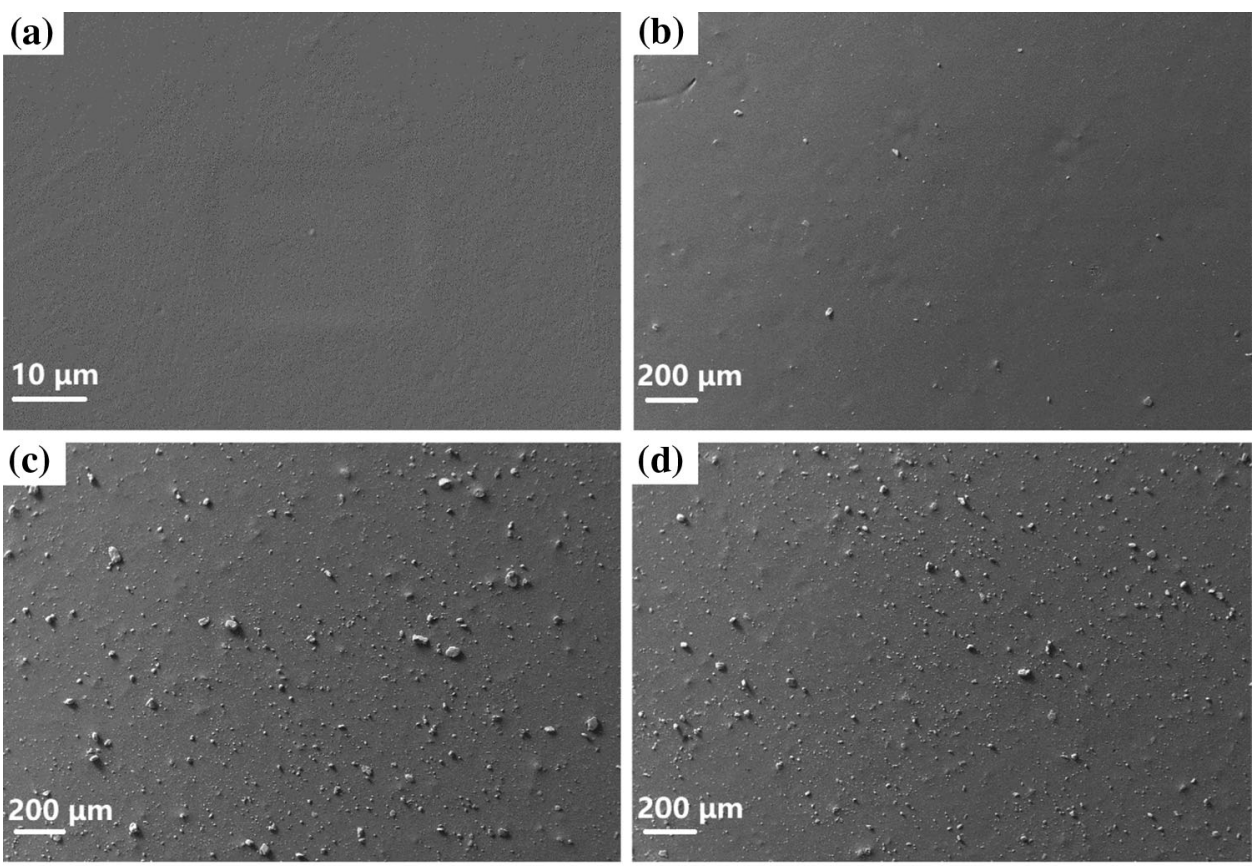

(e)
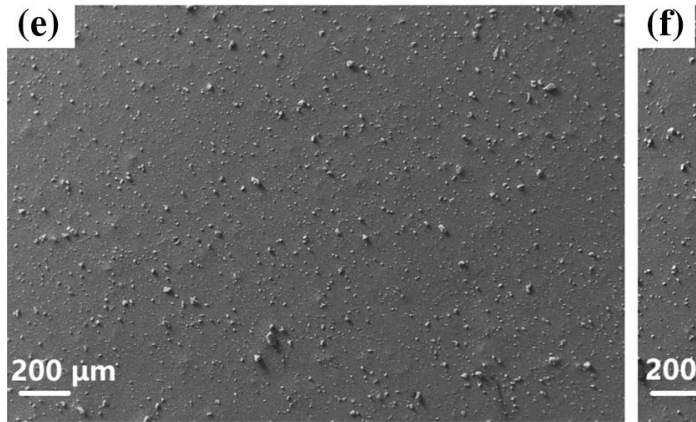

(f)

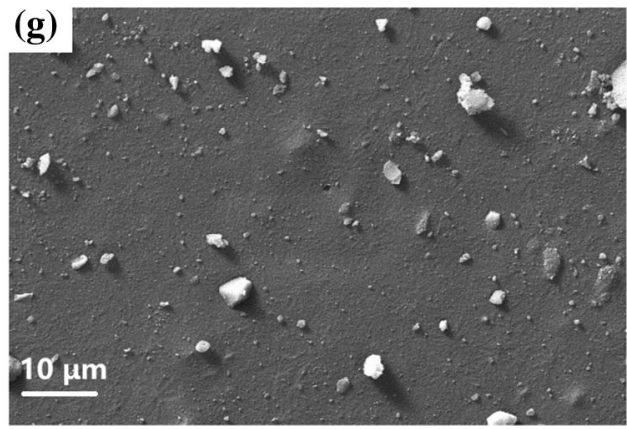

few attempts to explain the source of this peak. We suggest that this peak can be related to the (100) and (101) planes of carbon-based impurity in the as-received iPP. The crystallinity of each system was derived from the XRD patterns, and the results are shown in Table 1. A calculation method used in [38] was applied. The addition of nano-AlN shows a limited ability to alter the crystallinity of $\mathrm{PP}$, although an insignificant decrease $(4 \%)$ can be found when increasing the loading of C8M-treated AlN from 1 to
$10 \mathrm{wt} \%$. This was related to the hindrance effect on the growth of crystalline by the introduction of AIN [20]. The results of crystallinity are consistent with our previous work, where differential scanning calorimetry (DSC) was applied to $\mathrm{PP} /$ nano-AlN composites and on obvious change can be found in crystallinity when nano-AlN was introduced [5]. 
Figure $7 \mathrm{XRD}$ patterns of $\mathrm{PP} /$ nano-AlN composites indicating the $\alpha$-crystals can be observed in all samples, and the formation of $\beta$-crystal is evident in PP with MPStreated AIN. XRD patterns of the as-received AIN and PP are also included as a reference.

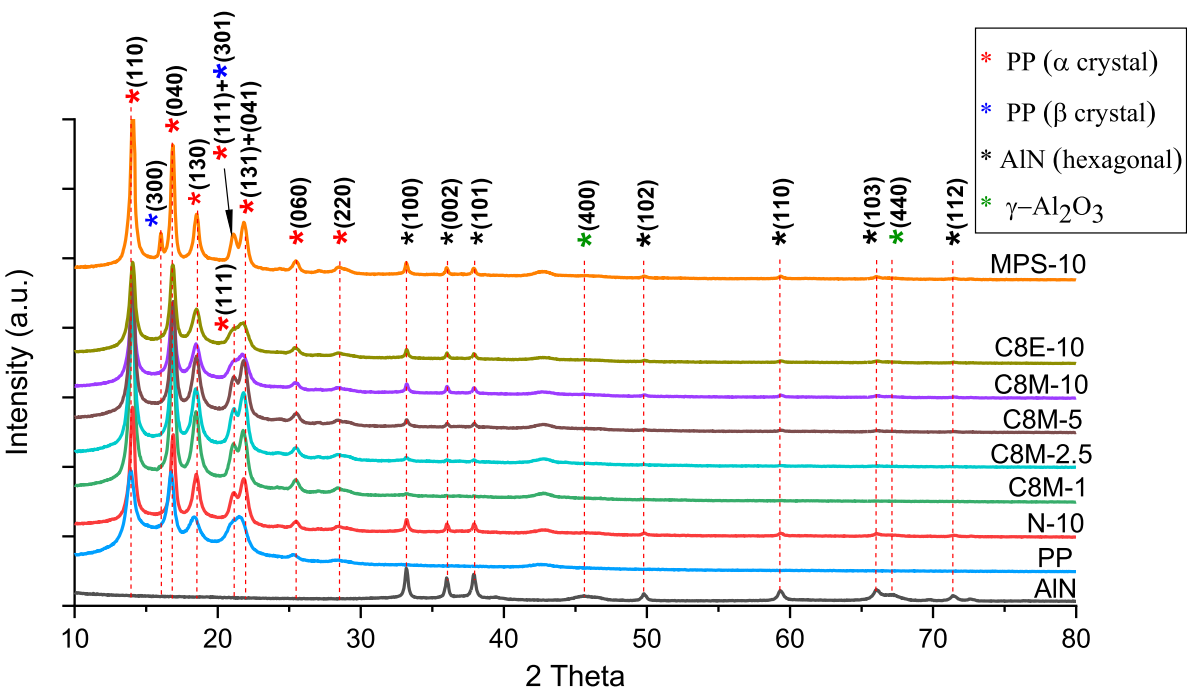

Table 1 Crystallinity of selected samples derived from XRD patterns and a calculation method used in [38] was applied

\begin{tabular}{llll}
\hline Samples & Crystallinity (\%) & Samples & Crystallinity (\%) \\
\hline As-received PP & 39 & C8M-5 & 40 \\
N-10 & 40 & C8M-10 & 38 \\
C8M-1 & 42 & C8E-10 & 38 \\
C8M-2.5 & 40 & MPS-10 & 41 \\
\hline
\end{tabular}

\section{Water absorption behaviour of PP/nano-AlN composites}

In Fig. 8, the weight increase in PP and composite samples after immersion in water for 9 days is presented, from which can be observed that the weight increase in all samples reaches almost saturation in 6 days or less. The weight of pure PP as reference shows, as expected, no dependence on water immersion due to its non-polar carbon chain structure, which has a very weak ability to absorb water. This along with the increase in water uptake with increased AlN loading (Fig. 8a) suggests that the weight increase in $\mathrm{PP} /$ nano-AlN composites is solely related to the incorporation of nano-AlN and water absorption onto its surfaces. Although all $\mathrm{PP} /$ nano-AlN composites show an increase in mass after immersing in water, the silane functionalisation has a significant effect on altering the issue of water absorption (Fig. 8b-d).

It is a surprising observation that there is no significant difference between samples treated with different SCA, especially for samples treated with polar (MPS) and non-polar (C8M, C8E) silanes. This indicates that the methacrylate group has less ability to absorb water than the $-\mathrm{OH}$ groups left on the surfaces of the non-treated AlN, or that the interaction with PP somehow alters the ability of the methacrylate group to absorb water. When compared to $\mathrm{PE} /$ nano-AlN composites as reported in earlier research [11], where PE with $10 \mathrm{wt} \%$ of AlN only has an uptake of water less than $0.1 \%$ of the total weight after immersing in water for 14 days, the higher weight increase for the non-treated samples $(0.29 \%$, Fig. 8) in the present work is likely related to the smaller particle size and thus the increased surface area (Fig. 3). It is worth noting that the weight increase in most $\mathrm{PP} /$ nano-AlN composites reaches almost saturation after only one day, with no further significant increase in weight after $24 \mathrm{~h}$. This might be related to the thickness of the water shell around nanoparticles: as Lau et al. [19] suggested, a thicker shell can gradually be formed surrounding a nanosilica particle during a long period (more than 14 days) after the water immersion, and a loss peak was found to move to the high-frequency range, while moisture uptake increases, which has also been numerically proved by Qiang et al. [12]. This will be explained in the results of dielectric response below.

\section{Results and discussion-dielectric properties}

\section{Complex permittivity}

The real $\left(\varepsilon^{\prime}\right)$ and imaginary $\left(\varepsilon^{\prime \prime}\right)$ permittivities of PP and a selection of $\mathrm{PP} /$ nano-AlN composites in dry 

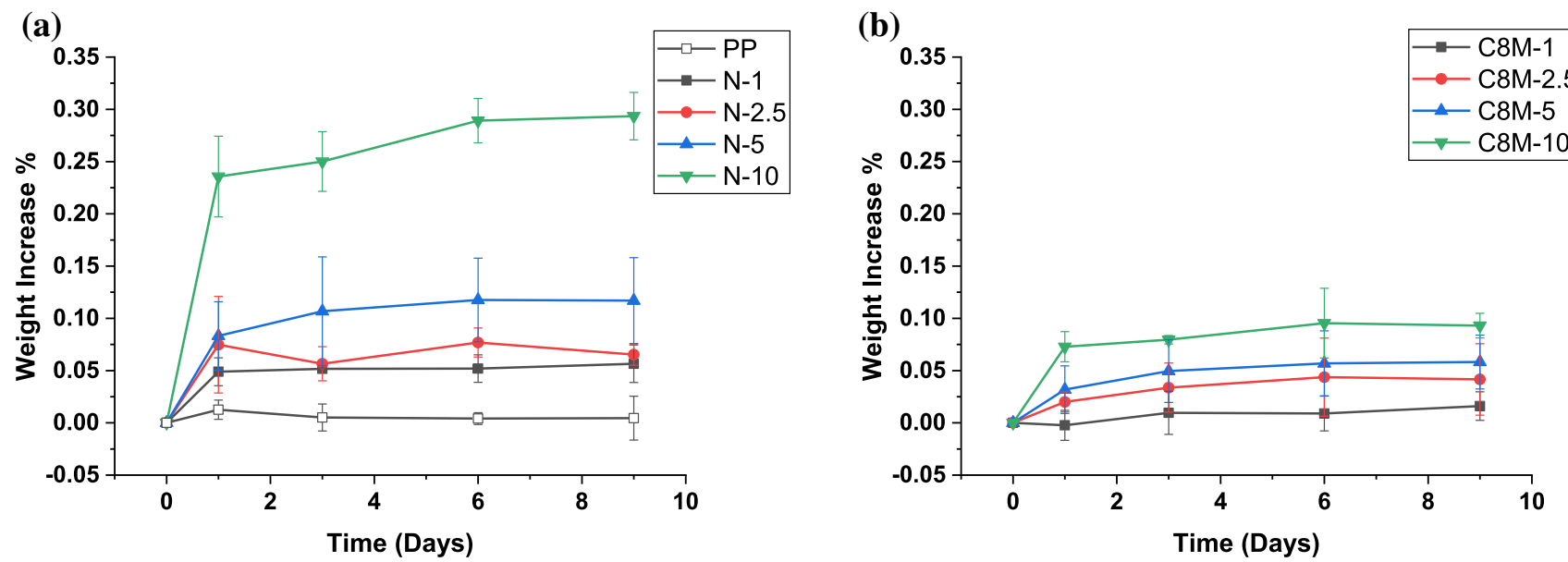

(c)

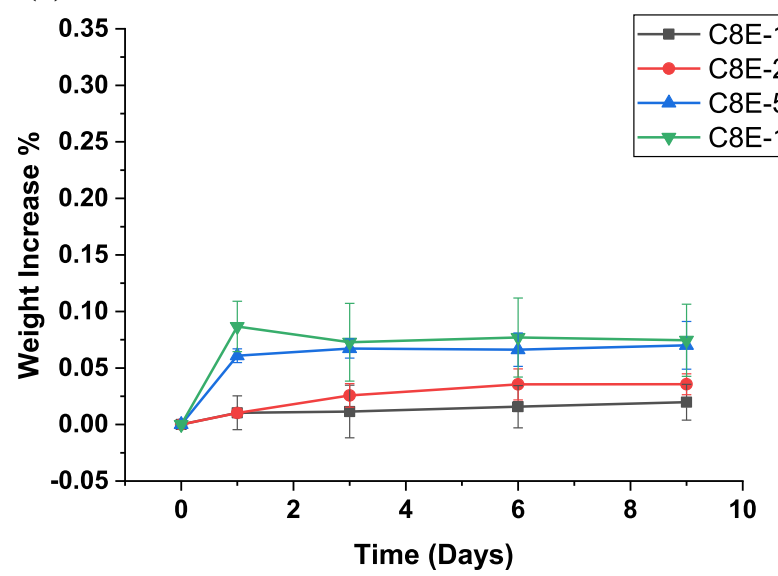

(d)

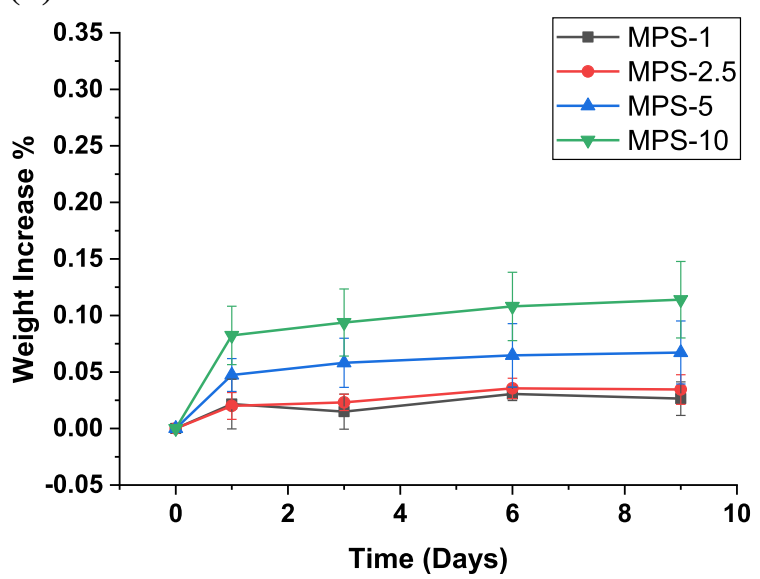

Figure 8 The weight increase in PP and composite samples after immersion in de-ionised water for 9 days at $20{ }^{\circ} \mathrm{C}$ : a PP and PP with non-treated AlN, b PP with C8M-treated AlN, c PP with C8E-treated AlN and d PP with MPS-treated AIN.

condition are plotted in Fig. 9. Filler loadings of 1, 2.5 and $5 \mathrm{wt} \%$ of the samples with SCA treatment were omitted for brevity, as they show identical results to their non-treated counterparts. The real permittivity shows an increase with the growth of the AlN loading ratio. However, $\mathrm{PP} /$ nano-AlN composites with different nanoparticle surface chemistry show little effect on the real permittivity, when considering the measurement uncertainties that arise from the sample thickness measurement, which can have up to \pm $0.1\left(\varepsilon^{\prime}\right)$ from multiple tests. The real permittivity of each sample (Fig. 9a) is a flat line throughout the tested frequency range at room temperature, due to the non-polar nature of PP. This also results in neat PP having a very low loss under an AC electric field. The imaginary permittivity (Fig. $9 \mathrm{~b}$ ) falls near to the minimum sensitivity of the instrument $\left(10^{-4}\right)$ in the case of non-filled PP and composites with a low loading ratio $(\leq 5 \mathrm{wt} \%)$. PP/nano-AlN composites filled with 10 wt $\%$ of AlN exhibit a slight upturn at low frequencies, but no significant difference is observed due to changing the nanoparticle surface chemistry under these dry conditions.

The real and imaginary permittivities of samples immersed in water for 9 days are shown in Fig. 10. From the real permittivity results in Fig. $10 a-d$, all $\mathrm{PP} /$ nano-AlN composites show an increase in the value of $\varepsilon^{\prime}$ compared to the dry samples and obvious upturns at low frequency can be observed for samples with 5 and $10 \mathrm{wt} \%$ non-treated AlN (Fig. 10a). When considering the magnitude of the upturns of $\mathrm{N}-10-\mathrm{W}$, it is evident that it shows higher values than $10 \mathrm{wt} \%$ AlN/PE composites in our previous work [11], where N-10-W gains more water $(0.29 \%)$ than that of $10 \mathrm{wt} \% \mathrm{AlN} / \mathrm{PE}(0.1 \%)$ after the curve reaches an almost saturation. Shaw et al. [39] highlighted an upturn with a similar $\varepsilon^{\prime}$ feature but with a significantly higher magnitude after immersing $5 \mathrm{wt} \%$ 
(a)

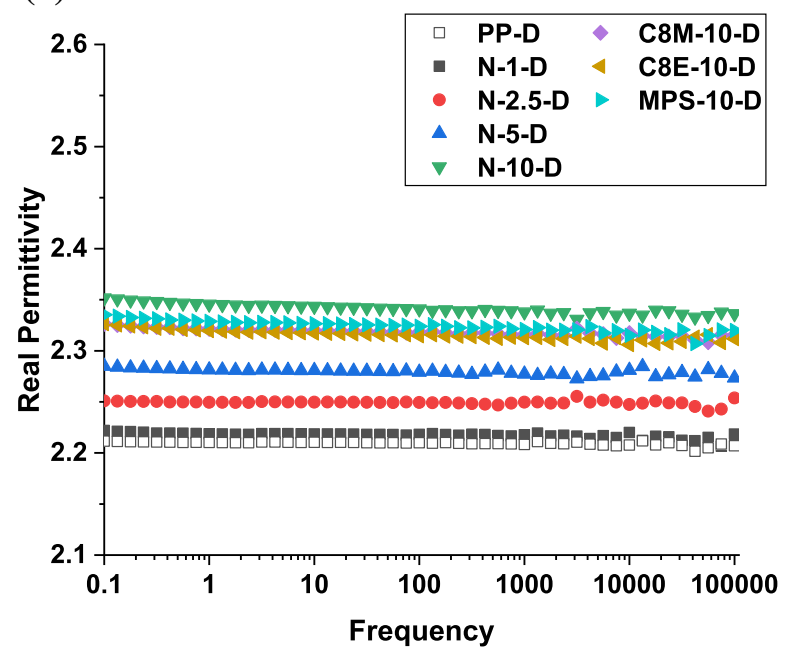

Figure 9 Complex permittivity of dry samples measured at $20{ }^{\circ} \mathrm{C}$ : a real part, $\mathbf{b}$ imaginary part, and dash line shows the minimum sensitivity of the instrument $\left(10^{-4}\right)$. Filler loadings of 1 ,

nano-clay/PP/EVA composites into a non-polar solvent, xylene, where the observed upturn has a low correlation with the reorientation of the polar molecules like water. Thus, we suggest that in this case, these upturns are likely to be caused by the interfacial polarisation and/or the polarisation effect due to water molecules. Although similar trends at low frequencies can also be seen in samples with silanetreated AlN (Fig. 10b-d), the magnitudes are significantly reduced with the help of the silane treatment, especially for samples treated with non-polar silanes, $\mathrm{C} 8 \mathrm{M}$ and $\mathrm{C} 8 \mathrm{E}$. It is not surprising that notably higher values of $\varepsilon^{\prime}$ are observed in MPS-10-W (Fig. 10d) than in any of its C8M and C8E functionalised counterparts; polar surface functional groups are the main reason.

Unlike the clearly visible loss peaks at high frequencies $\left(10^{3}-10^{5} \mathrm{~Hz}\right)$ in imaginary permittivity, which result from water uptake [11, 13, 20], most samples show a monotonic upturn at low frequency in Fig. 11. Significant upturns can be seen for nontreated AlN (Fig. 11a), and peaks are located in the low-frequency range $(<50 \mathrm{~Hz})$. The relaxation frequency is related to the thickness of the water shell and the mobility of the resulting water clusters [11-13]; PP/nano-AlN composites show a low water absorption ability, e.g. N-10-W can only gain $0.29 \%$ of weight, while a $10 \mathrm{wt} \%$ non-treated nanosilica/PE composite shows more than $1.6 \%$ weight increase and relaxation peaks at $10^{3}-10^{5} \mathrm{~Hz}$ can be observed (b)

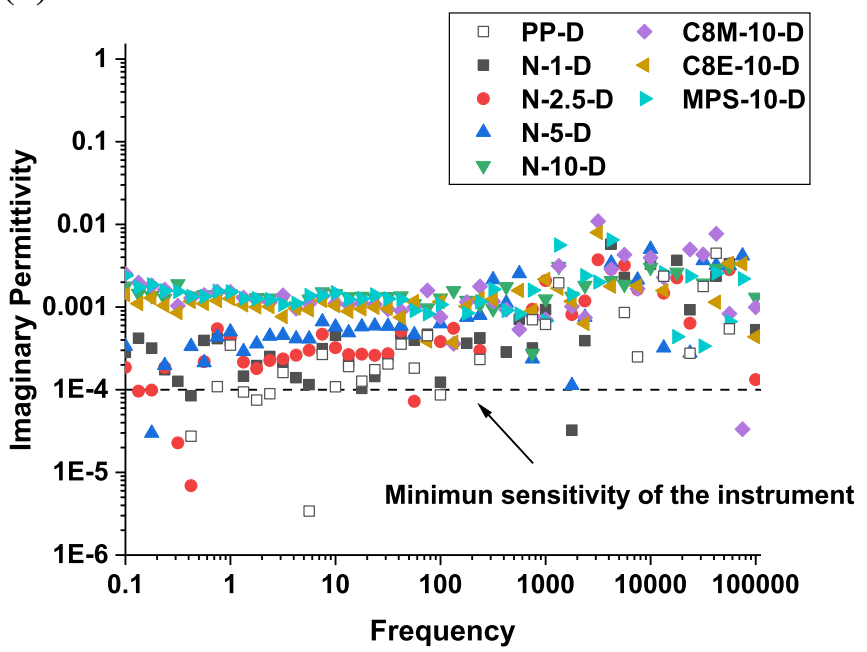

2.5 and $5 \mathrm{wt} \%$ of the samples with SCA treatment were omitted for brevity, as they show identical results to their non-treated counterparts.

[19]. As a result, much of the water is located close to the core of the AlN nanoparticles here and the resulting decrease in mobility shifts the relaxation peak to low frequencies. As the loading ratio increases, the mobility of the water shells will be restricted by its overlapping, which will result in the relaxation peak shifted to a lower frequency as observed in Fig. 11a [40].

Consistent with the real permittivity, the C8M- and C8E-treated samples show identical results in the imaginary part (Fig. 11b, c). An increase in the magnitude of $\varepsilon^{\prime \prime}$ with the AlN loading can be seen, but the relaxation peaks are now expected existing at much lower frequencies $<0.1 \mathrm{~Hz}$ compared to the nontreated systems. The $\mathrm{C} 8$ silane treatment can displace a great amount $-\mathrm{OH}$ on the AlN surface and therefore less is available to trap water on the nanoparticle surface; this is evinced by the water measurements shown in Fig. 8b, c, and the associated relaxations are shifted to lower frequencies. Nevertheless, the water absorption results clearly show that the octyl silanetreated PP/nano-AlN composites can still absorb some water, and one possible explanation for this is the displacement of $-\mathrm{OH}$ is incomplete by $\mathrm{C} 8$ silane treatment. Alternatively, in addition to the hydroxyl group from the $\mathrm{Al}-\mathrm{OH}$ on the AlN surface, polar sites other than the $\mathrm{Al}-\mathrm{OH}$, e.g. the $\mathrm{Si}-\mathrm{OH}$ from the silane treatment (Fig. 1a) and surface Al- $\mathrm{NH}_{2}$, can also contribute to the weight gain of samples during water immersion [5, 41]. Besides, identical results provided 

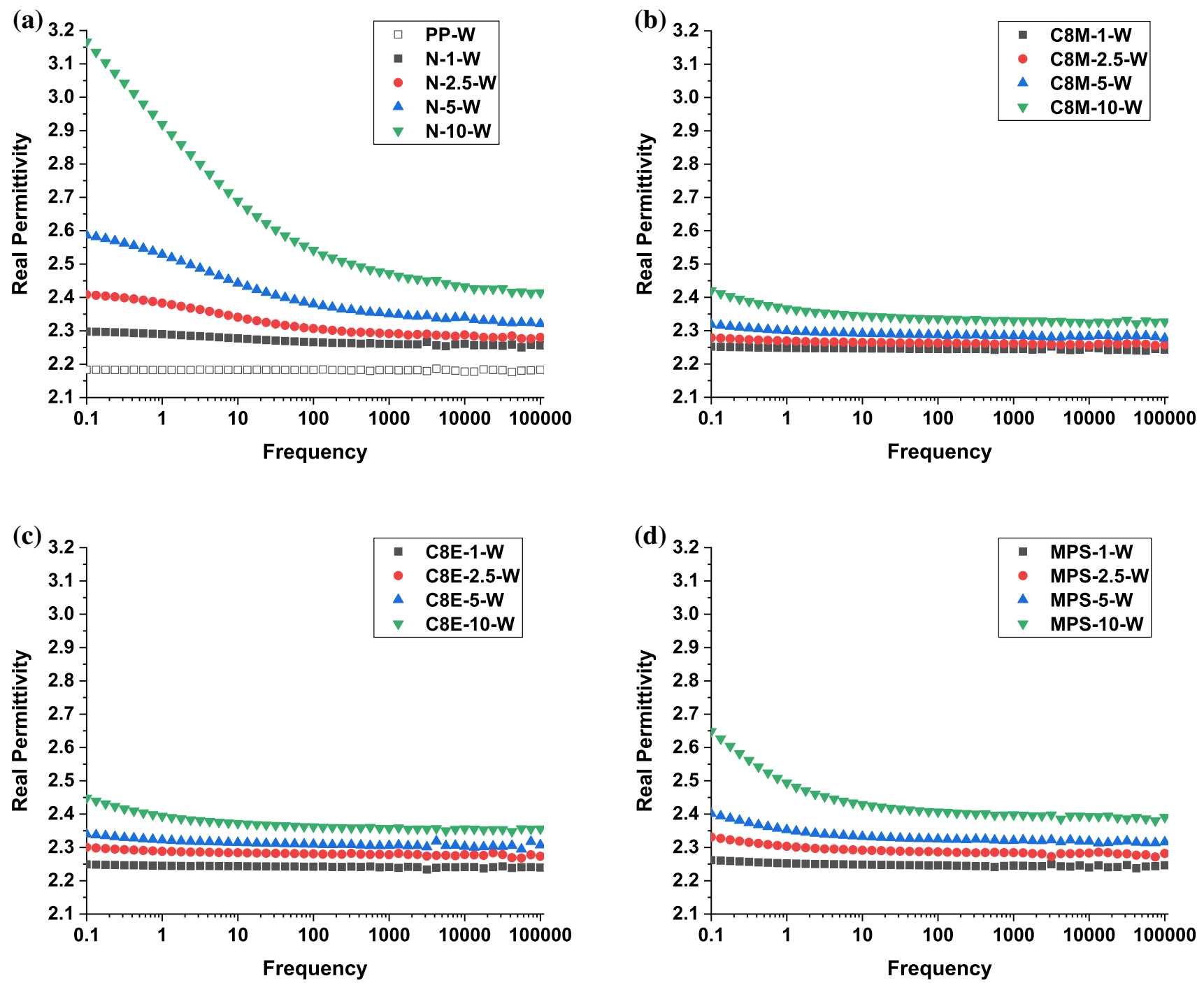

Figure 10 The real permittivity of wet samples (after 9 days water immersion) measured at $20{ }^{\circ} \mathrm{C}$ : a PP and non-treated samples, $\mathbf{b} \mathrm{C} 8 \mathrm{M}$ treated samples, c C8E-treated samples and $\mathbf{d}$ MPS-treated samples.

by $\mathrm{C} 8 \mathrm{M}$ - and $\mathrm{C} 8 \mathrm{E}$-treated composites indicate that the assumption of the thick SCA layer introducing more hydrophilic sites (Fig. 1a, outstretched $\mathrm{Si}-\mathrm{OH}$ ) is not the determining factor in the change of the dielectric response [5].

MPS-treated samples show higher imaginary permittivity than the C8-treated samples with the same loading ratios (Fig. 11d), and this is related to the presence of the methacrylate group. The increase in the slope of the imaginary curves of MPS-10-W indicates a relaxation feature at lower frequencies. While these might be revealed by performing measurements at elevated temperatures, this was not performed in current work, as it would result in loss of absorbed water, therefore negating comparability with results at lower temperatures. Nevertheless, a similar relaxation feature can be observed in our previous work, where dry samples were tested at $90{ }^{\circ} \mathrm{C}[5]$.

\section{AC breakdown strength}

AC breakdown strength of dry and wet (immersed for 9 days) samples with 5 and $10 \mathrm{wt} \%$ of filler loading is shown in Fig. 12, and two-parameter Weibull scale and shape parameters of all samples are listed in Table 2. The breakdown strength of nonfilled PP (Fig. 12a) is not dependent on water immersion due to its non-polar structure; consistent with this is the parallel observation of no weight gain 


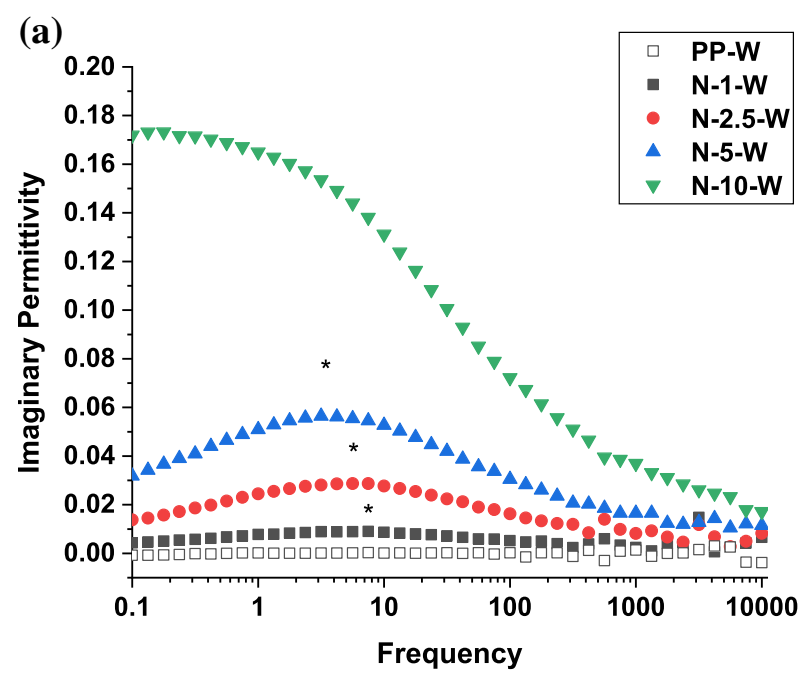

(c)

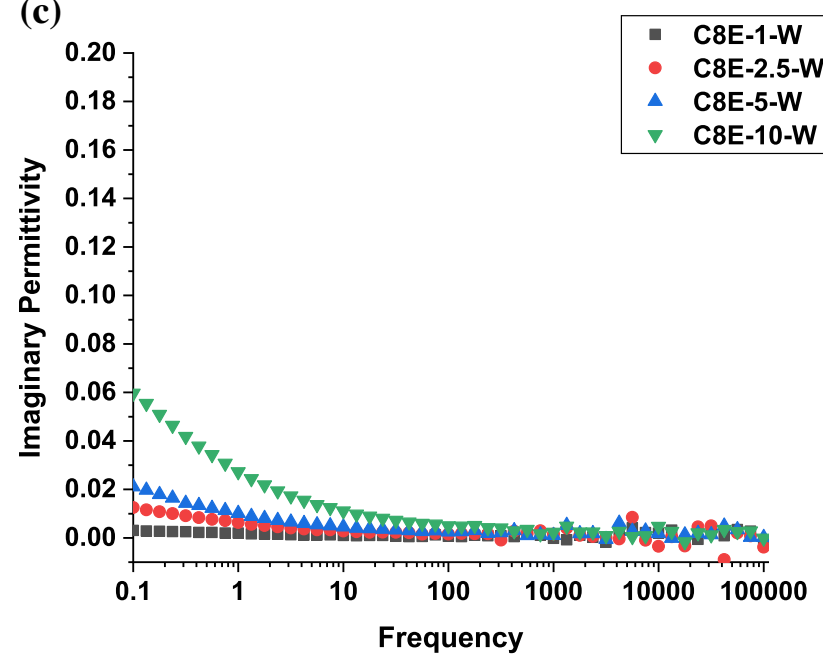

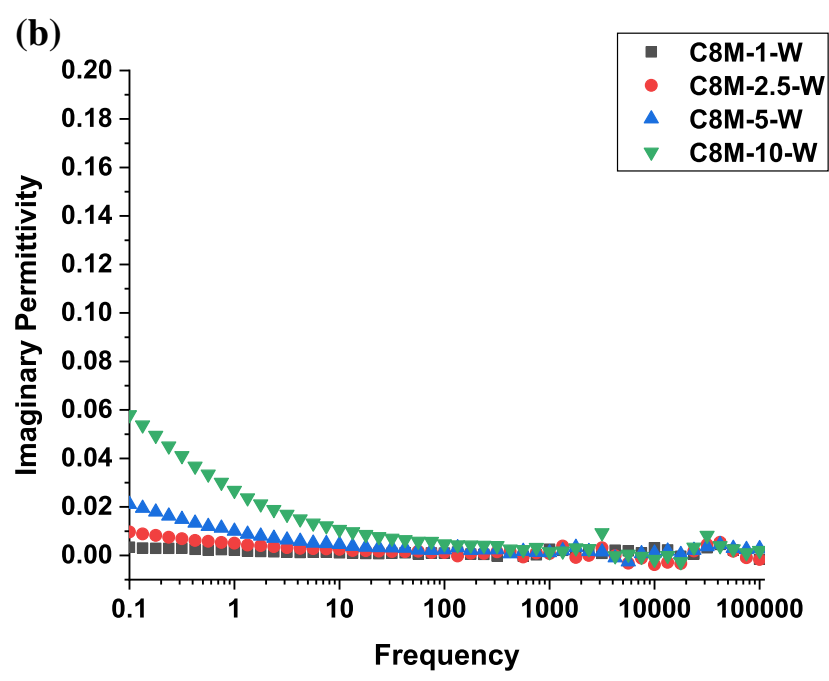

(d)

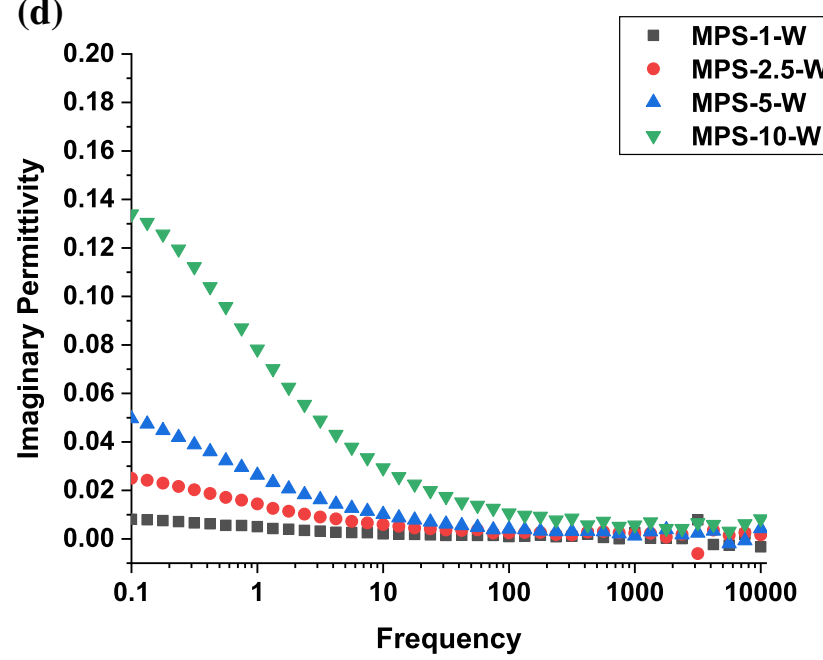

Figure 11 The imaginary permittivity of wet samples (after 9 days water immersion) measured at $20{ }^{\circ} \mathrm{C}$ : a PP and non-treated samples, b C8M-treated samples, c C8E-treated samples and d MPS-treated samples.

after water immersion (Fig. 8a). No obvious increase in AC breakdown strength can be achieved after incorporating nano-AlN into PP under any conditions of water immersion or surface treatment. Instead, all $\mathrm{PP} /$ nano-AlN composites, regardless of surface treatment method, show a monotonic decreasing trend with increased AlN loading. Consistent results were also reported where non-treated and C8E-treated AlN were added into PE and PP, respectively [11, 42].

For dry samples, different silane treatments can help to slightly enhance the AC breakdown strength, relative to counterparts employing non-treated AlN. MPS-treated samples show higher AC breakdown strength than the $\mathrm{C} 8$ samples, and this can be related to the presence of $\beta$-crystal in MPS samples (Fig. 7) [43]. After 9-day water immersion, a significant $(\sim 35 \mathrm{kV} / \mathrm{mm})$ reduction in the $\mathrm{AC}$ breakdown of non-treated systems can be observed (Fig. 12a), while C8M and C8E (Fig. 12b, c) exhibit much less of a decrease $(\sim 20 \mathrm{kV} / \mathrm{mm})$ when compared to the nonfilled PP. Ayoob et al. [16] reported that a $30 \mathrm{wt} \%$ $\mathrm{BN} / \mathrm{PE}$ sample did not show an obvious reduction in AC breakdown strength after 14 days of water immersion $(0.08 \%$ weight gain) which is similar to both sets of C8-treated samples here. Although wet MPS-treated samples (Fig. 12d) show a reduction in AC breakdown strength relative to their dry counterparts, they still show a value consistent with the wet C8-treated samples. This could be related to the 
(a)

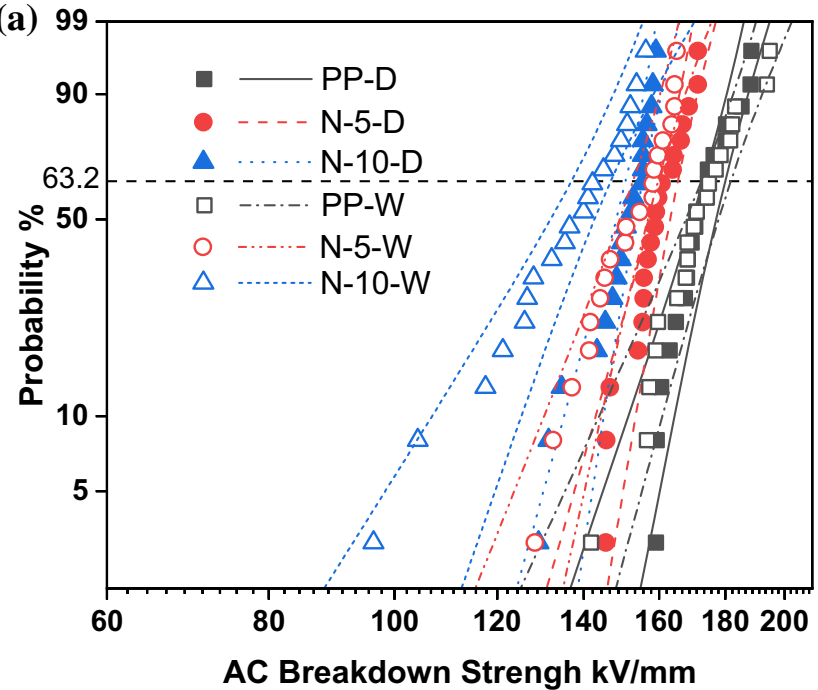

(c)

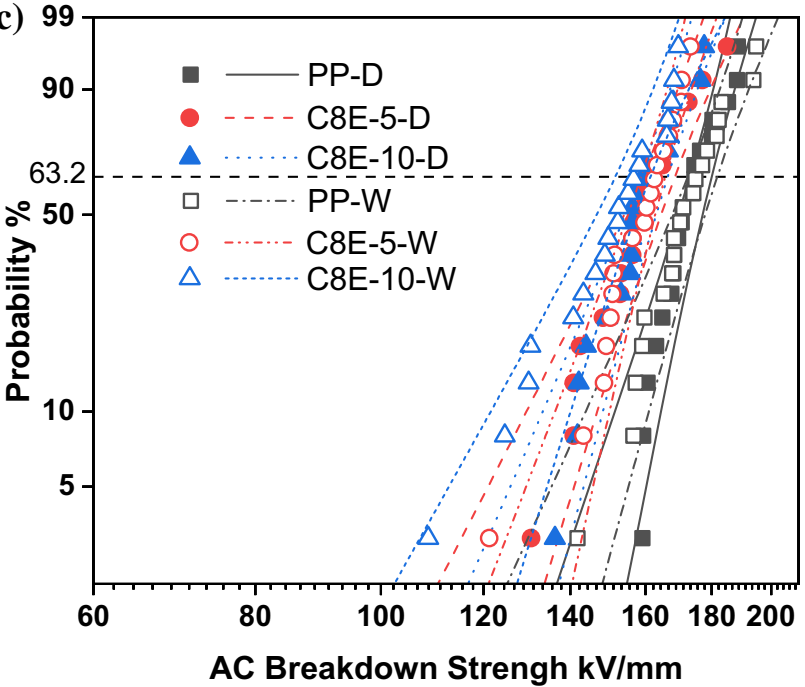

(b)

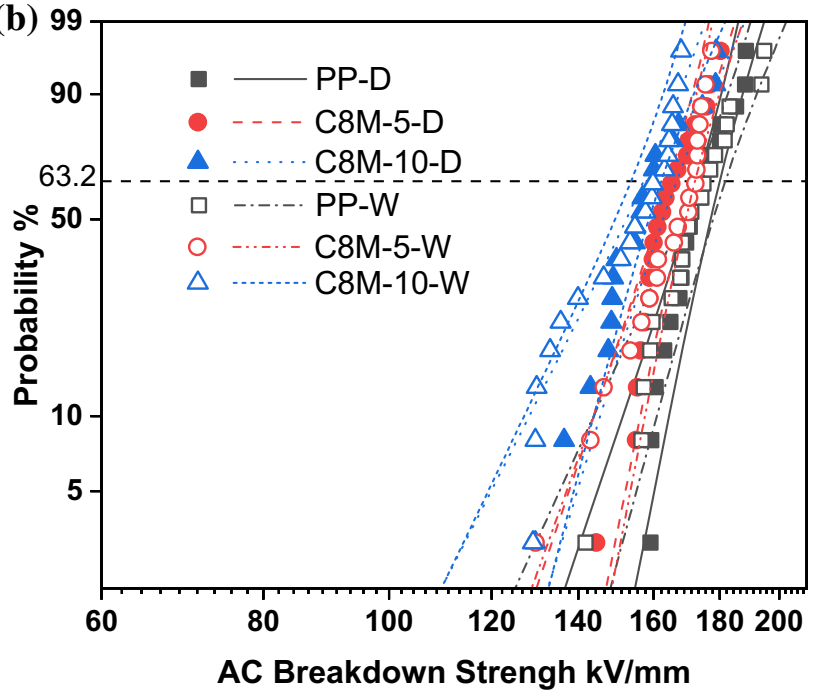

(d)

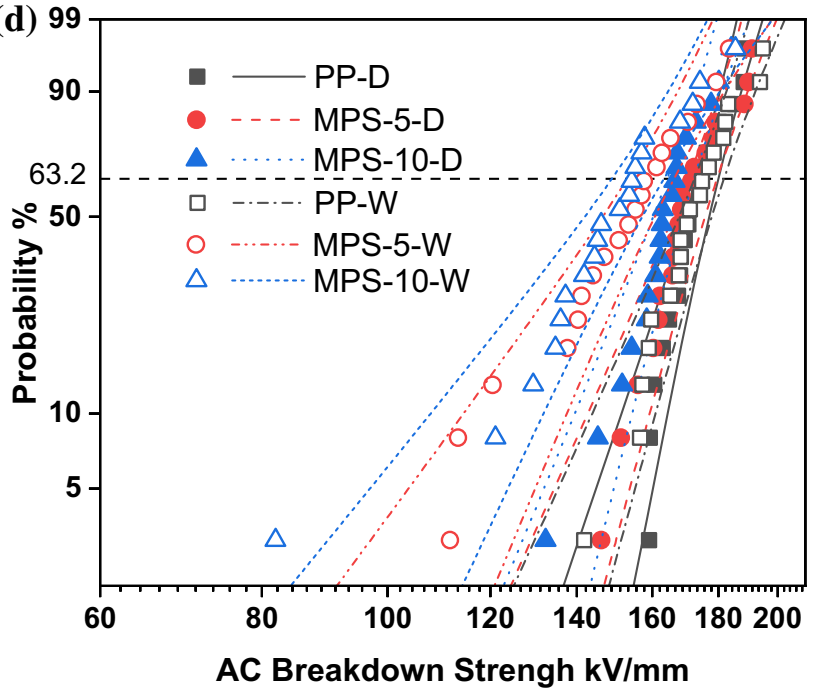

Figure $12 \mathrm{AC}$ breakdown strength of dry and wet samples $(0,5$ and $10 \mathrm{wt} \%)$ tested at $20{ }^{\circ} \mathrm{C}$ and $50 \mathrm{~Hz}$, a PP and non-treated samples, b PP and C8M treated samples, $\mathbf{c}$ PP and C8E treated samples, $\mathbf{d}$ PP and MPS treated samples.

same level of water uptake, as shown in Fig. 8, suggesting that $\mathrm{AC}$ breakdown tests are a less sensitive probe of dielectric properties than dielectric spectroscopy; in the latter data sets (Fig. 11), MPS samples exhibited a higher dielectric loss relative to their C8 silane-treated counterparts.

\section{Conclusions}

The hydrolytic instability of AIN and the resulting sensitivity of the particle surface chemistry, and subsequently the morphology, to humidity are discussed. This rigorous study using SEM, TEM, XRD and TGA of the as-received AIN verified the above- mentioned sensitivity to humidity, as well as the AlN nanoscale, and the presence of the $\gamma$-alumina is evident.

The influence of AlN surface chemistry (treated with different modifiers) on the crystal phases, water absorption kinetics, complex dielectric response and AC breakdown strength of polypropylene/AIN under "dry" and "wet" sample conditioning has been examined in this work.

It is noteworthy that the introduction of MPStreated AlN can induce the formation of the $\beta$-crystal (trigonal) from XRD patterns. In contrast, the incorporation of non-treated and C8-treated systems shows no ability in changing the crystal phase of the 
Table 2 AC breakdown strength and Weibull parameters of all samples under dry and wet conditions

\begin{tabular}{lllllr}
\hline Filler & Filler loading & $\alpha, \mathrm{kV} / \mathrm{mm}$, Dry & $\beta$-Dry & $\alpha, \mathrm{kV} / \mathrm{mm}$, Wet & $\beta$-Wet \\
\hline Non-filled & 0 & 176.5 & 20.2 & 177.1 & 14.8 \\
Non-treated & 1 & 172.3 & 14.4 & 166.0 & 9.2 \\
& 2.5 & 165.0 & 12.4 & 165.2 & 15.8 \\
& 5 & 162.8 & 23.9 & 156.2 & 17.4 \\
& 10 & 153.0 & 25.3 & 141.8 & 11.1 \\
C8M & 1 & 171.0 & 20.6 & 179.1 & 18.3 \\
& 2.5 & 169.4 & 27.2 & 170.5 & 14.4 \\
& 5 & 167.6 & 20.3 & 168.9 & 19.6 \\
& 10 & 161.9 & 13.3 & 157.9 & 14.5 \\
C8E & 1 & 170.1 & 14.3 & 170.3 & 11.4 \\
& 2.5 & 169.0 & 17.8 & 166.4 & 17.1 \\
& 5 & 163.7 & 13.1 & 162.2 & 17.9 \\
& 10 & 162.4 & 15.7 & 156.5 & 12.4 \\
MPS & 1 & 177.8 & 21.3 & 178.4 & 13.2 \\
& 2.5 & 178.1 & 19.5 & 166.2 & 7.3 \\
& 5 & 175.0 & 15.1 & 159.6 & 9.3 \\
& 10 & 168.3 & 16.4 & 156.0 & 8.4 \\
\hline
\end{tabular}

non-filled PP. From the AC breakdown strength of the dry samples, it is suggested the higher values of the MPS-treated samples compared to composites with non-treated or C8-treated AlN are related to the presence of the $\beta$-crystal. But overall, from SEM results, the derived crystallinity from XRD patterns and the dielectric properties under dry conditions, it can be concluded that the influence of the filler surface chemistry on the morphology of PP, and its resulting effect on the dielectric properties of $\mathrm{PP} /$ nano-AlN composites, is insignificant.

In contrast, the filler surface chemistry shows a significant impact on the dielectric properties after samples were immersed in water. Composites employing non-treated AlN tend to absorb more water during water immersion tests due to a higher density of surface hydroxyl sites. This issue can be effectively minimised with the help of surface modification, especially with silanes with non-polar organofunctional groups, C8. Benefiting from the improved hydrophobicity, the silane-treated samples show a significantly higher ability to retain permittivity and AC breakdown strength than their nontreated counterparts following water immersion. Although MPS-treated samples show an almost identical hydrophobicity to the samples treated by octyl silanes, it would be reasonable to believe that the greater reduction in AC breakdown strength and the higher dielectric loss after exposure to water are coming from the presence of the polar methacrylate groups in MPS-treated samples.

The present work demonstrates clearly the importance of the hydrophobicity of nanoscale filler or similar sized additives used in HV insulation under wet operating conditions and proves that surface functionalisation is an effective approach to mitigate the water absorption issue. As the dielectric properties of polymeric insulating materials are very sensitive to the presence of water, the benefit of introducing functional groups and the resulting interaction between the additives and the PP matrix, such as MPS-induced $\beta$-crystals, and the hence increased AC breakdown strength, can be quickly undone by absorbed water from a humid environment settling on said additives. A balance must be found between the additional functionality required by an additive and the hydrophobicity of said additives, especially for insulating materials that will be subjected to high humidity environments during operation.

\section{Supplementary information}

Fourier-transform infrared spectroscopy (FTIR) and thermal gravimetric analysis (TGA) verification of the treated AlN are omitted here because they can be 
found in previous work, where it is evident that the silane functionalisation was successful $[5,26]$.

The real $\left(\varepsilon^{\prime}\right)$ and imaginary $\left(\varepsilon^{\prime \prime}\right)$ permittivities of PP and a selection of $\mathrm{PP} /$ nano-AlN composites under dry condition are plotted in Fig. 9. Filler loadings of 1, 2.5 and $5 \mathrm{wt} \%$ of the samples with SCA treatment were omitted for brevity, as they show identical results to their non-treated counterparts.

\section{Compliance with ethical standards}

Conflicts of interest The authors declare no conflict of interest.

Open Access This article is licensed under a Creative Commons Attribution 4.0 International License, which permits use, sharing, adaptation, distribution and reproduction in any medium or format, as long as you give appropriate credit to the original author(s) and the source, provide a link to the Creative Commons licence, and indicate if changes were made. The images or other third party material in this article are included in the article's Creative Commons licence, unless indicated otherwise in a credit line to the material. If material is not included in the article's Creative Commons licence and your intended use is not permitted by statutory regulation or exceeds the permitted use, you will need to obtain permission directly from the copyright holder. To view a copy of this licence, visit http://creativecommons.org/licen ses/by/4.0/.

\section{References}

[1] Hosier IL, Vaughan AS, Pye A, Stevens GC (2019) High performance polymer blend systems for HVDC applications. IEEE Trans Dielectr Electr Insul 26(4):1197-1203. https://d oi.org/10.1109/TDEI.2019.007954

[2] Huang X, Fan Y, Zhang J, Jiang P (2017) Polypropylene based thermoplastic polymers for potential recyclable HVDC cable insulation applications. IEEE Trans Dielectr Electr Insul 24(3):1446-1456. https://doi.org/10.1109/TDEI.2017. 006230

[3] Andritsch T, Vaughan AS, Stevens GC (2017) Novel insulation materials for high voltage cable systems. IEEE Electr Insul Mag 33(4):27-33. https://doi.org/10.1109/MEI.2017. 7956630

[4] Huang X, Jiang P, Tanaka T (2011) A review of dielectric polymer composites with high thermal conductivity. IEEE
Electr Insul Mag 27(4):8-16. https://doi.org/10.1109/MEI.2 011.5954064

[5] Wang X, Andritsch T, Chen G, Virtanen S (2019) The role of the filler surface chemistry on the dielectric and thermal properties of polypropylene aluminium nitride nanocomposites. IEEE Trans Dielectr Electr Insul 26(3):1009-1017. h ttps://doi.org/10.1109/TDEI.2019.007773

[6] Zhu BL, Ma J, Wu J, Yung KC, Xie CS (2010) Study on the properties of the epoxy-matrix composites filled with thermally conductive AIN and BN ceramic particles. J Appl Polym Sci 118(5):2754-2764. https://doi.org/10.1002/app. 32673

[7] Gu J, Zhang Q, Dang J, Zhang J, Yang Z (2009) Thermal conductivity and mechanical properties of aluminum nitride filled linear low-density polyethylene composites. Polym Eng Sci 49(5):1030-1034. https://doi.org/10.1002/pen. 21336

[8] Danikas MG, Tanaka T (2009) Nanocomposites-a review of electrical treeing and breakdown. IEEE Electr Insul Mag 25(4):19-25. https://doi.org/10.1109/MEI.2009.5191413

[9] Nelson JK, Fothergill JC, Dissado LA, Peasgood W (2002) Towards an understanding of nanometric dielectrics. IEEE Conf Electr Insul Dielectr Phen Cancun Mexico. https://doi. org/10.1109/ceidp.2002.1048793

[10] Takada T, Hayase Y, Tanaka Y, Okamoto T (2008) Space charge trapping in electrical potential well caused by permanent and induced dipoles for LDPE/MgO nanocomposite. IEEE Trans Dielectr Electr Insul 15(1):152-160. https://doi. org/10.1109/T-DEI.2008.4446746

[11] Hosier IL, Praeger M, Vaughan AS, Swingler SG (2017) The effects of water on the dielectric properties of aluminum based nanocomposites. IEEE Trans Nanotechnol 16(4):667-676. https://doi.org/10.1109/TNANO.2017. 2703982

[12] Qiang D, Wang Y, Chen G, Andritsch T (2018) Dielectric properties of epoxy silica and boron nitride nanocomposites and moisture/temperature influences. IET Nanodielectr 1(1):48-59. https://doi.org/10.1049/iet-nde.2017.0002

[13] Hosier IL, Praeger M, Vaughan AS, Swingler SG (2017) The effects of water on the dielectric properties of silicon-based nanocomposites. IEEE Trans Nanotechnol 16(2):169-179. h ttps://doi.org/10.1109/tnano.2016.2642819

[14] Zou C, Fothergill JC, Rowe SW (2007) A "water shell” model for the dielectric properties of hydrated silica-filled epoxy nano-composites. IEEE Int Conf Solid Dielectr Winchester UK. https://doi.org/10.1109/icsd.2007.4290834

[15] Virtanen S, Vaughan AS, Yang L, Saiz F, Quirke N (2016) Dielectric breakdown strength and electrical conductivity of low density polyethylene octylnanosilica composite. IEEE 
Conf Electr Insul Dielectr Phen Toronto Canada. https://doi. org/10.1109/ceidp.2016.7785608

[16] Ayoob, R (2017) Dielectric properties of hexagonal boron nitride polymer nanocomposites. Ph.D. Thesis, University of Southampton

[17] Lee E-S, Lee S-M, Shanefield DJ, Cannon WR (2008) Enhanced thermal conductivity of polymer matrix composite via high solids loading of aluminum nitride in epoxy resin. J Am Ceram Soc 91(4):1169-1174. https://doi.org/10.1111/j. 1551-2916.2008.02247.x

[18] Yu S, Hing P, Hu X (2002) Thermal conductivity of polystyrene-aluminum nitride composite. Compos Part A Appl Sci Manuf 33(2):289-292. https://doi.org/10.1016/S1359-8 35X(01)00107-5

[19] Lau KY, Vaughan AS, Chen G, Hosier IL, Holt AF (2013) On the dielectric response of silica-based polyethylene nanocomposites. J Phys D Appl Phys 46(9):095303. https://d oi.org/10.1088/0022-3727/46/9/095303

[20] Hosier IL, Praeger M, Holt AF, Vaughan AS, Swingler SG (2017) On the effect of functionalizer chain length and water content in polyethylene/silica nanocomposites: part I- dielectric properties and breakdown strength. IEEE Trans Dielectr Electr Insul 24(3):1698-1707. https://doi.org/10.11 09/TDEI.2017.005788

[21] Wang S, Chen P, Yu S, Zhang P, Li J, Li S (2018) Nanoparticle dispersion and distribution in XLPE and the related DC insulation performance. IEEE Trans Dielectr Electr Insul 25(6):2349-2357. https://doi.org/10.1109/TDEI. 2018.007156

[22] Xie Y, Hill CAS, Xiao Z, Militz H, Mai C (2010) Silane coupling agents used for natural fiber/polymer composites: a review. Compos Part A Appl Sci Manuf 41(7):806-819. h ttps://doi.org/10.1016/j.compositesa.2010.03.005

[23] Andritsch T, Kochetov R, Morshuis PH, Smit JJ (2010) Short term DC breakdown and complex permittivity of A12O3- and MgO-epoxy nanocomposites. IEEE Conf Electr Insul Dielectr Phen West Lafayette USA. https://doi.org/10. 1109/CEIDP.2010.5723960

[24] Yeung C, Vaughan AS (2016) On the effect of nanoparticle surface chemistry on the electrical characteristics of epoxybased nanocomposites. Polymer 8(4):126. https://doi.org/10. 3390/polym8040126

[25] Zhao S, Cheng L, Leng J, Guo L, Gao Y, Zheng Y, Cao D (2016) Synergistic enhancement of glass fiber and tetrapodshaped $\mathrm{ZnO}$ whisker on the mechanical and thermal behavior of isotactic polypropylene. J Appl Polym Sci 133(46):44217. https://doi.org/10.1002/app.44217

[26] Wang X, Andritsch T, Chen G (2018) Effect of surface functionalization on the dielectric properties of polypropylene aluminium nitride nanocomposites. IEEE Int Conf
Dielectr Budapest Hungary. https://doi.org/10.1109/icd.201 8.8514621

[27] Olley R, Bassett D (1982) An improved permanganic etchant for polyolefines. Polymer 23(12):1707-1710. https://doi.org/ 10.1016/0032-3861(82)90110-0

[28] Li J, Nakamura M, Shirai T, Matsumaru K, Ishizaki C, Ishizaki K (2006) Mechanism and kinetics of aluminum nitride powder degradation in moist air. J Am Ceram Soc 89(3):937-943. https://doi.org/10.1111/j.1551-2916.2005.00 767.x

[29] Zhou L, Zhuang W, Wang X, Yu K, Yang S, Xia S (2017) Potential acute effects of suspended aluminum nitride (AlN) nanoparticles on soluble microbial products (SMP) of activated sludge. J Environ Sci 57:284-292. https://doi.org/10. 1016/j.jes.2017.02.001

[30] Wozniak M, Rutkowski P, Kata D (2016) Rheological properties and thermal conductivity of AlN-poly (propylene glycol) suspensions. Heat Mass Transf 52(1):103-112. http s://doi.org/10.1007/s00231-015-1597-0

[31] Liu C, Xu Y, Bi D, Luo B, Zhang F, Wang T, Yao Y, Lu S et al (2019) The effects of aluminum-nitride nano-fillers on the mechanical, electrical, and thermal properties of high temperature vulcanized silicon rubber for high-voltage outdoor insulator applications. Mater. 12(21):3562. https://doi. org/10.3390/ma12213562

[32] Li YQ, Qiu T, Xu J (1997) Effect of thermal oxidation treatment in air on the hydrolysis of AlN powder. Mater Res Bull 32(9):1173-1179. https://doi.org/10.1016/S0025-5408( 97)00093-7

[33] Elagin AA, Beketov AR, Baranov MV, Shishkin RA (2013) Aluminum nitride. Preparation methods. Refract Ind Ceram 53(6):395-403. https://doi.org/10.1007/s11148-013-9546-2

[34] Sickafus KE, Wills JM, Grimes NW (1999) Structure of spinel. J Am Ceram Soc 82(12):3279-3292. https://doi.org/ 10.1111/j.1151-2916.1999.tb02241.x

[35] Paglia G, Božin ES, Billinge SJL (2006) Fine-scale nanostructure in $\gamma$-Al2O3. Chem Mater 18(14):3242-3248. http s://doi.org/10.1021/cm060277j

[36] Sarkar M, Dana K, Ghatak S, Banerjee A (2008) Polypropylene-clay composite prepared from Indian bentonite. Bull Mater Sci 31(1):23-28. https://doi.org/10.1007/ s12034-008-0005-5

[37] Liang Y, Wen S, Ren Y, Liu L (2015) Fabrication of nanoprotrusion surface structured silica nanofibers for the improvement of the toughening of polypropylene. RSC Adv 5(40):31547-31553. https://doi.org/10.1039/C5RA01510C

[38] Machado G, Denardin E, Kinast E, Gonçalves M, De Luca M, Teixeira S, Samios D (2005) Crystalline properties and morphological changes in plastically deformed isotatic polypropylene evaluated by X-ray diffraction and 
transmission electron microscopy. Eur Polym J 41(1):129-138. https://doi.org/10.1016/j.eurpolymj.2004.08. 011

[39] Shaw AV, Vaughan AS, Andritsch T (2019) The dielectric effect of xylene on an organoclay-containing composite. IEEE Trans Dielectr Electr Insul 26(3):890-897. https://doi. org/10.1109/TDEI.2019.007854

[40] Ayoob R, Alhabill FN, Andritsch T, Vaughan AS (2018) The effect of water absorption on the dielectric properties of polyethylene hexagonal boron nitride nanocomposites. J Phys D Appl Phys 51(6):065307. https://doi.org/10.1088/ 1361-6463/aaa306

[41] Baraton M-I, Chen X, Gonsalves KE (1996) FTIR analysis of the surface of nanostructured aluminium nitride powder prepared via chemical synthesis. J Mater Chem 6(8):1407-1412. https://doi.org/10.1039/JM9960601407
[42] Zhou Y, Hu J, Chen X, Yu F, He J (2016) Thermoplastic polypropylene/aluminum nitride nanocomposites with enhanced thermal conductivity and low dielectric loss. IEEE Trans Dielectr Electr Insul 23(5):2768-2776. https://doi.org/ 10.1109/tdei.2016.7736836

[43] Zhang C, Zha J-W, Yan H-D, Li W-K, Dang Z-M (2018) High improvement in trap level density and direct current breakdown strength of block polypropylene by doping with a $\beta$-nucleating agent. Appl Phys Lett 112(9):091902. http s://doi.org/10.1063/1.5020736

Publisher's Note Springer Nature remains neutral with regard to jurisdictional claims in published maps and institutional affiliations. 